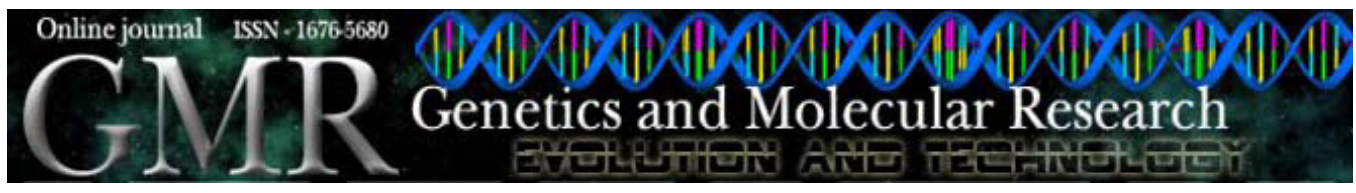

\title{
Genetic analysis of two new quantitative trait loci for ear weight in maize inbred line Huangzao4
}

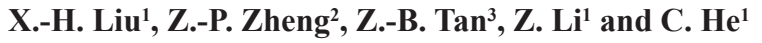 \\ ${ }^{1}$ Key Laboratory of Southwest China Wildlife Resources Conservation \\ (Ministry of Education), China West Normal University, \\ Nanchong City, P.R. China \\ ${ }^{2}$ Nanchong Institute of Agricultural Sciences, Nanchong City, P.R. China \\ ${ }^{3}$ Beijing IPE Bio-Technology Co., Ltd., Beijing City, P.R. China \\ Corresponding author: Z.-P. Zheng \\ E-mail: 1xhxhsfdx@yahoo.com.cn
}

Genet. Mol. Res. 9 (4): 2140-2147 (2010)

Received March 22, 2010

Accepted July 23, 2010

Published November 3, 2010

DOI 10.4238/vol9-4gmr858

\begin{abstract}
Ear weight is one of the most important agronomic traits considered necessary in maize (Zea mays L.) breeding projects. To determine its genetic basis, a population consisting of 239 recombinant inbred lines, derived from the cross Mo17 x Huangzao4, was used to detect quantitative trait loci (QTLs) for ear weight under two nitrogen regimes. Under a high nitrogen fertilization regime, one QTL was identified in chromosome bin $2.08-2.09$, which explained $7.46 \%$ of phenotypic variance and an increase in ear weight of about $5.79 \mathrm{~g}$, owing to an additive effect. Under a low nitrogen regime, another QTL was identified in chromosome bin 1.10-1.11; it accounted for $7.11 \%$ of phenotypic variance and a decrease of $5.24 \mathrm{~g}$ in ear weight, due to an additive effect. Based on comparisons with previous studies, these two QTLs are new loci associated with ear weight in maize. These findings contribute to our knowledge about the genetic basis of ear weight in maize.
\end{abstract}

Key words: Maize (Zea mays L.); Ear weight; Quantitative trait locus; Nitrogen regime; Recombinant inbred line 


\section{INTRODUCTION}

Ear weight $(\mathrm{EW})$ is a very important trait in maize (Zea mays L.) breeding programs related to yield (Cross, 1985), but at present, a maize germplasm with high EW is quite lacking. To resolve this problem, an effective solution is to utilize elite genes associated with EW to improve the trait. However, this first needs understanding of its genetic basis, and quantitative trait locus (QTL) mapping is an efficient approach to determine the genetic basis.

At present, some QTLs associated with EW have been mapped on maize chromosomes (Frova et al., 1999; Xiang et al., 2001; Xiao et al., 2005; Guo et al., 2008; Sabadin et al., 2008), but, different parental lines, ecological conditions or population could lead to different results such as QTL number, location and effect. For example, using the $\mathrm{F}_{2}$ population from the cross X178 x B73, Xiao et al. (2005) identified two QTLs on chromosomes 1 and 9 under well-water environment, while under water-stressed environment, three QTLs were located on chromosomes 1, 2 and 9. Although nitrogen $(\mathrm{N})$ is one of the most important nutrients affecting many agronomic traits including EW (Ribaut et al., 2007), previous studies reported on ecological conditions designed for QTL identification for EW focused on different water environments (Frova et al., 1999; Xiao et al., 2005; Guo et al., 2008) and did not consider different N regimes.

Moreover, QTL mapping must depend on desirable parental lines. Inbred line Huangzao4, from the Tangsipingtou heterotic group, is one of the elite maize resources in P. R. China; besides high EW and yield, the material has many other merits, including high combining ability, wide adaptability and strong resistance to most pathogens in maize (Zhao et al., 2008; Liu et al., 2009). Currently, Huangzao4 has been widely developed and utilized at the molecular level, such as gene cloning, QTL identification and genetic transformation (Wu et al., 2002; Zhao et al., 2008; Wang et al., 2009), but to date, the QTLs associated with EW in Huangzao4 have not been evaluated.

Therefore, in the present study, Huangzao4 as one parent for constructing the recombinant inbred line (RIL) population and genetic map and two $\mathrm{N}$ regimes were used to detect the QTLs for EW in maize. The objectives were 1) to identify the QTLs associated with EW from new germplasm, and 2) to more clearly determine the genetic basis of EW in maize.

\section{MATERIAL AND METHODS}

\section{Plant materials}

The experimental materials involved in this study included two parental inbred lines Huangzao4 and Mo17, $\mathrm{F}_{1}$ and an $\mathrm{F}_{9}$ RIL population consisting of 239 RILs. Huangzao4 and Mo17 are the representative lines of the Tansipingtou and Lancaster heterotic groups, respectively. The $\mathrm{F}_{1}$ and RIL population were derived from the cross between the two lines.

\section{Field experiments and statistical analyses}

All 242 lines were sown in a complete randomized design with six replicates at Nanchong Institute of Agricultural Sciences, Nanchong City, P. R. China, with single-plant planting, 15 plants per row and one ear per plant in one replicate. Three replicates were under high $\mathrm{N}$ regime (HNR) by applying $300 \mathrm{~kg} / \mathrm{ha}$ urea, and the other three were under low $\mathrm{N}$ regime 
(LNR) with no added $\mathrm{N}$ fertilizer. The average contents of total $\mathrm{N}$ and alkaline hydrolysis $\mathrm{N}$ in 30 -cm depth soil were 0.092 and $0.000056 \%$, respectively.

During harvest, the middle eight plants of each line of every replicate were individually investigated for the trait EW. The data for the RIL population were analyzed by the SPSS11.5 software (www.spss.com), using descriptive statistics, analysis of variance (ANOVA) and correlation analysis.

\section{QTL mapping}

Based on the phenotypic data of the RIL population under two $\mathrm{N}$ regimes and the reported genetic map covering $1421.5 \mathrm{cM}$ of mapping distance using 100 simple sequence repeat markers by Liu et al. (2009), the QTLs associated with EW were identified by composite interval mapping (CIM) of the Windows QTL Cartographer 2.5 software (Wang et al., 2010), $2.0 \mathrm{cM}$ as walk speed and $\log _{10}$ of odds ratio (LOD) 2.5 as QTL significance threshold based on previous studies (Qi et al., 1998; Gilliland et al., 2006). Control parameters included standard CIM model, 5 control markers, $10-\mathrm{cM}$ window size, and forward regression method. The QTLs with an LOD value greater than the threshold value were evaluated, and their positions, genetic effects and percentage of phenotypic variation were estimated at the significant LOD peak in the region. The identified QTLs were mapped with the Mapchart 2.1 software (Voorrips, 2002).

\section{RESULTS}

\section{Phenotypic observation and statistical analysis}

The results for EW showed that the lines tested showed variations. For the three lines Mo17, Huangzao4 and $F_{1}, F_{1}$ had much higher values than parental lines under either of the two $\mathrm{N}$ regimes (Table 1), which could be explained by heterosis. Under HNR, Huangzao4 had a higher EW value than did Mo17, while the opposite was obtained under LNR. For the RIL population, the 239 RILs under both $\mathrm{N}$ regimes provided significant differences in EW ( $\mathrm{P}<$ 0.001 ) (Table 2). Nevertheless, the data obtained under the two $\mathrm{N}$ regimes for the two groups showed a significant positive correlation at the 0.001 level $(r=0.876)$.

\begin{tabular}{|c|c|c|c|c|}
\hline Nitrogen regime & Mo17 & \multicolumn{2}{|c|}{ Huangzao4 } & $\mathrm{F}_{1}$ \\
\hline $\begin{array}{l}\text { HNR } \\
\text { LNR }\end{array}$ & $\begin{array}{l}51.87 \\
60.36\end{array}$ & \multicolumn{2}{|c|}{$\begin{array}{l}71.25 \\
57.31\end{array}$} & $\begin{array}{l}209.36 \\
190.09\end{array}$ \\
\hline \multicolumn{5}{|c|}{$\mathrm{HNR}=$ high nitrogen regime; $\mathrm{LNR}=$ low nitrogen regime } \\
\hline Nitrogen regime & Variation sources & Mean square & $\mathrm{F}$ & $\mathrm{P}$ \\
\hline HNR & $\begin{array}{l}\text { Between groups } \\
\text { Within groups }\end{array}$ & $\begin{array}{r}1326.36 \\
160.16\end{array}$ & $8.28 * * *$ & $<0.001$ \\
\hline LNR & $\begin{array}{l}\text { Between groups } \\
\text { Within groups }\end{array}$ & $\begin{array}{r}1132.06 \\
139.74\end{array}$ & $8.10^{* * *}$ & $<0.001$ \\
\hline
\end{tabular}

***Significant different at $\mathrm{P}<0.001 . \mathrm{HNR}=$ high nitrogen regime; $\mathrm{LNR}=$ low nitrogen regime. 
The results of the descriptive statistics for the RIL population are shown in Table 3. The RIL population under HNR had lower values than those under LNR for all the statistical parameters except standard deviation and coefficient of variation. From the frequency distribution graphs of the RIL population under the two $\mathrm{N}$ regimes (Figures 1 and 2), both groups showed a normal distribution, which suggests that the trait $\mathrm{EW}$ is probably a quantitative trait controlled by multiple genes.

Table 3. Descriptive statistics of recombinant inbred line population on ear weight.
\begin{tabular}{lcccccccc}
\hline Nitrogen regime & Range (g) & Minimum $(\mathrm{g})$ & Maximum $(\mathrm{g})$ & Mean $(\mathrm{g})$ & $\mathrm{SD}$ & $\mathrm{CV}(\%)$ & Skewness & Kurtosis \\
\hline HNR & 137.32 & 12.81 & 150.13 & 65.80 & 21.03 & $31.96 \%$ & 0.238 & 0.632 \\
LNR & 137.61 & 19.12 & 156.73 & 68.40 & 19.43 & $28.40 \%$ & 0.294 & 1.287 \\
\hline
\end{tabular}

$\mathrm{SD}=$ standard deviation; $\mathrm{CV}=$ coefficient of variation; $\mathrm{HNR}=$ high nitrogen regime; $\mathrm{LNR}=$ low nitrogen regime.

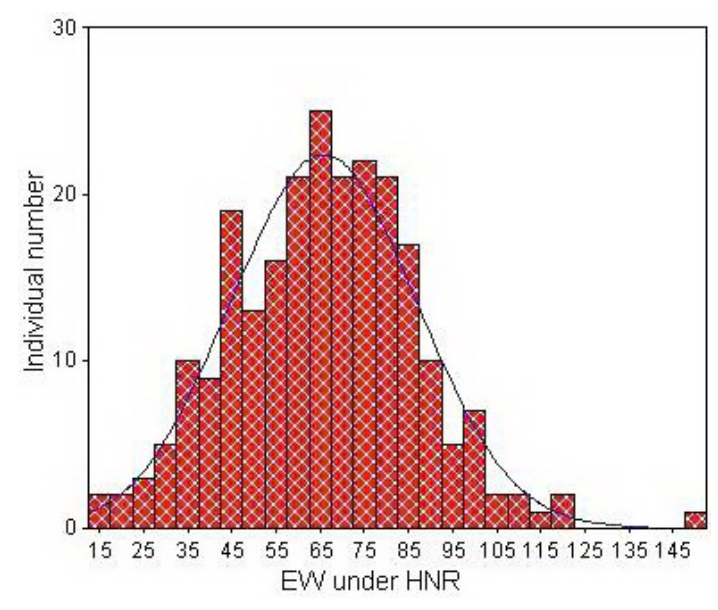

Figure 1. Frequency distribution of recombinant imbred line population for ear weight (EW) under high nitrogen regime (HNR).

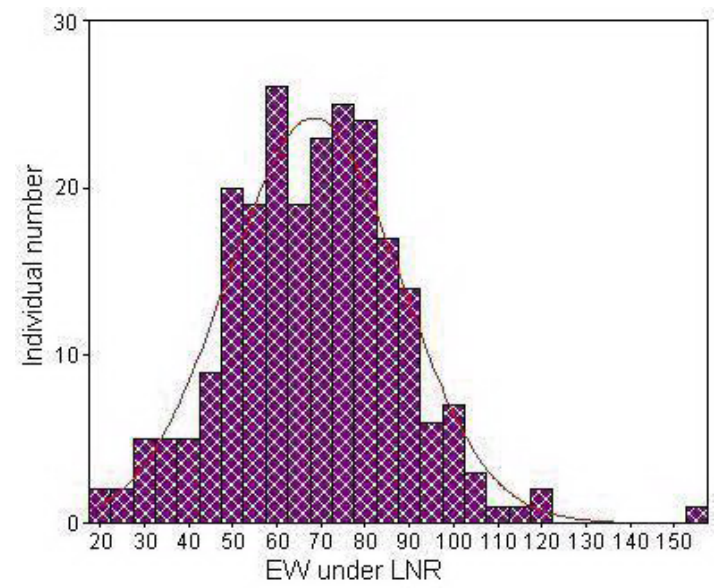

Figure 2. Frequency distribution of recombinant imbred line population for ear weight (EW) under low nitrogen regime (LNR). 


\section{QTL identification}

CIM was used to map the QTLs for EW, and as a result, two QTLs were detected with LOD threshold set 2.5 (Figures 3 and 4). Their chromosomal positions are displayed in Figure 5. The QTL identified under HNR (named Qew-hn-1) was on chromosome 2, near to Bnlg1520 with $7.7 \mathrm{cM}$ of mapping interval (Table 4); it could explain $7.46 \%$ of phenotypic variance and an increase in EW of $5.79 \mathrm{~g}$ due to its positive additive effect. While the other QTL identified under LNR (named Qew-ln-1) was located on chromosome 1 near to Phi308707 with $4.0 \mathrm{cM}$ of mapping interval, it could account for $7.11 \%$ of phenotypic variance and a decrease in EW of about $5.24 \mathrm{~g}$ owing to a negative additive effect. According to phenotypic data of the two parental lines and genetic effects of QTLs (Tables 1 and 4), the two QTLs in this study should be from Huangzao4: one caused an increase in EW, while the other a decrease.

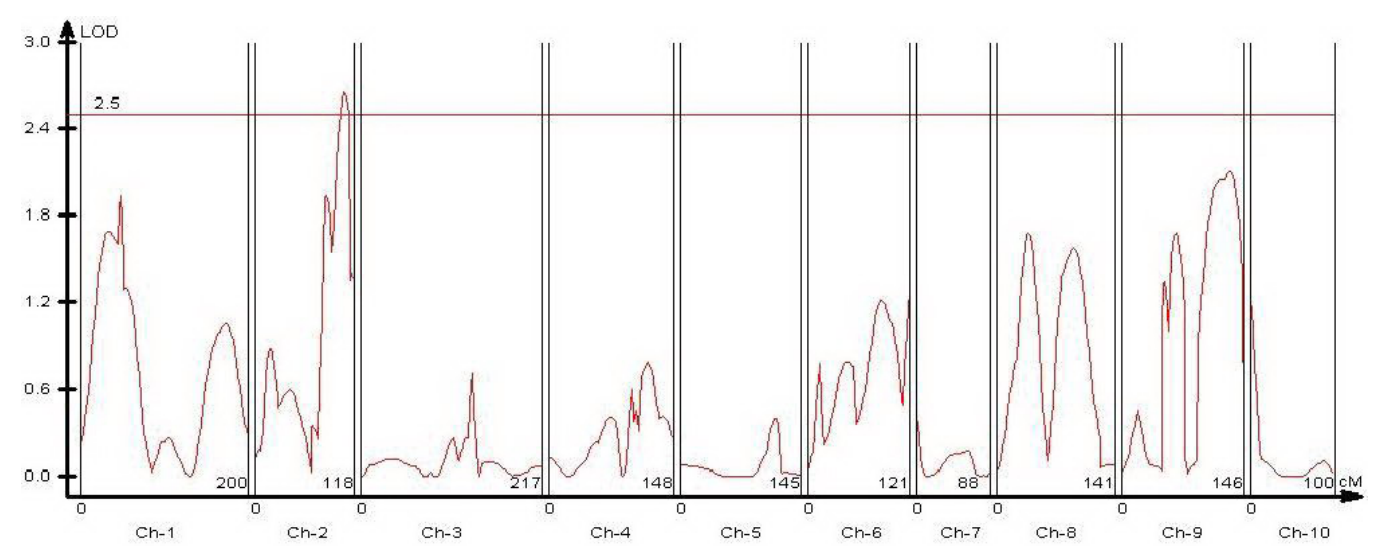

Figure 3. Quantitative trait loci scanning associated with ear weight under high nitrogen regime by composite interval mapping.

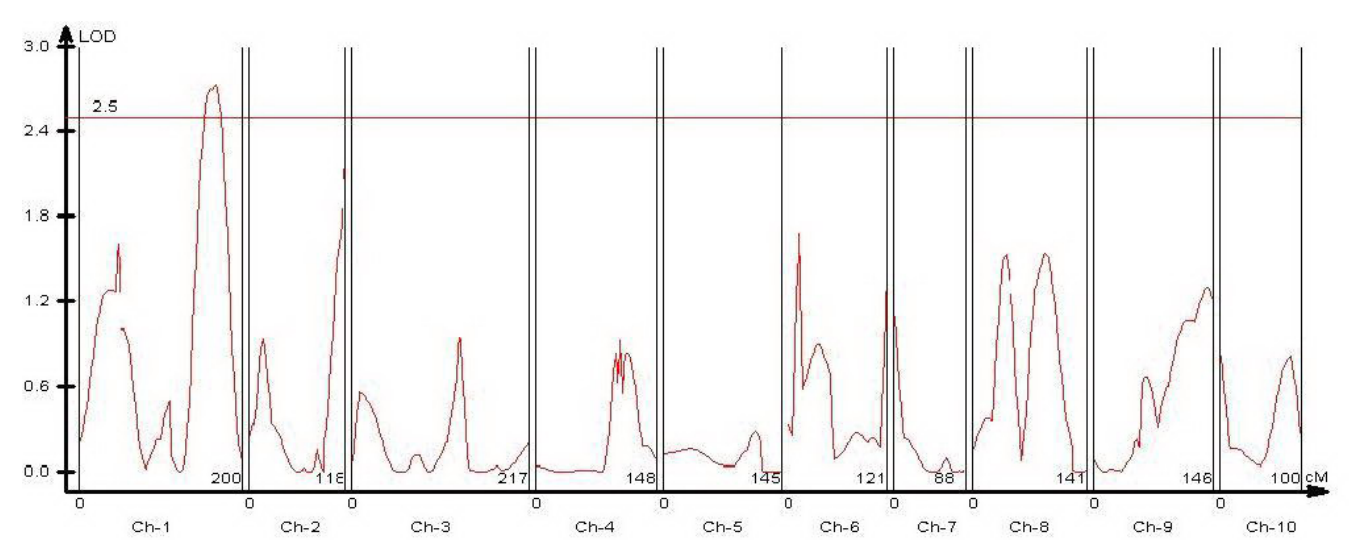

Figure 4. Quantitative trait loci scanning associated with ear weight under low nitrogen regime by composite interval mapping. 
$\mathrm{Ch}-1$

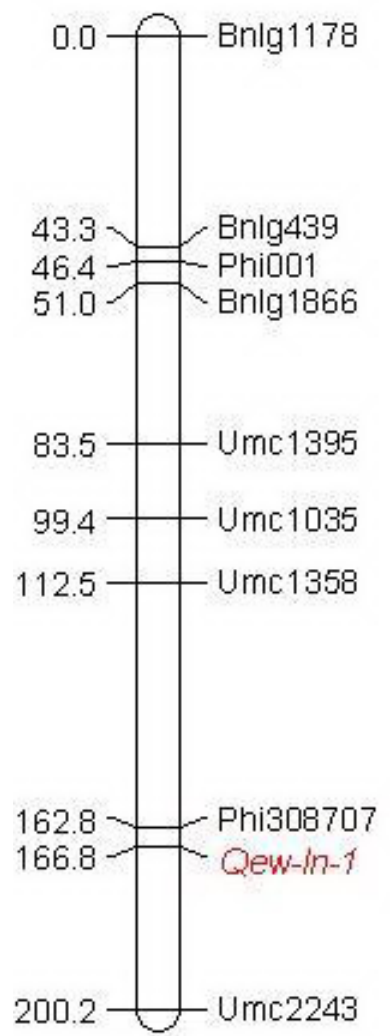

$\mathrm{Ch}-2$

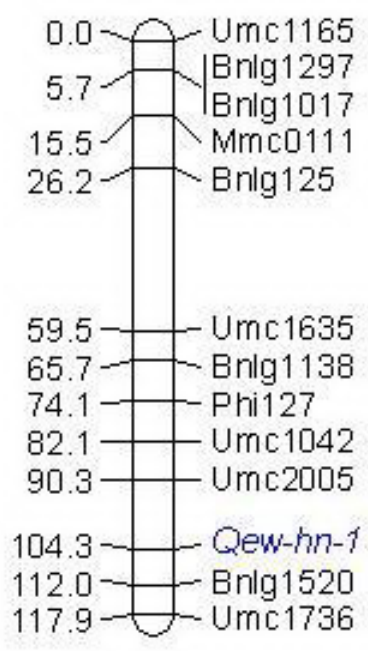

Figure 5. Chromosomal positions of the quantitative trait loci for ear weight identified using recombinant imbred line population under two nitrogen regimes. Qew- $h n-1$ on chromosome 2 (blue) and Qew-ln-1 on chromosome 1 (red) were identified under high and low nitrogen regimes, respectively.

Table 4. Positions and effects of the quantitative trait loci (QTLs) associated with ear weight by composite
interval mapping in maize.
\begin{tabular}{llclcccc} 
Nitrogen regime & QTL & Chr. & Flanking marker & Position (cM) & LOD & $R^{2}(\%)$ & Additive effect \\
\hline HNR & Qew- $h n-1$ & 2 & Umc2005-Bnlg1520 & 104.3 & 2.66 & $7.46 \%$ & 5.79 \\
LNR & Qew-ln-1 & 1 & Phi308707-Umc2243 & 166.8 & 2.74 & $7.11 \%$ & -5.24 \\
\hline
\end{tabular}

$\mathrm{LOD}=\log _{10}$ of odds ratio; HNR $=$ high nitrogen regime; $\mathrm{LNR}=$ low nitrogen regime.

\section{DISCUSSION}

Ear weight is one of the most important traits considered necessary in maize breeding projects related to yield. However, at present, its genetic basis has not been clearly understood, despite some reports on QTL mapping for the trait (Frova et al., 1999; Xiao et al., 2005; Guo et al., 2008; Sabadin et al., 2008). To more clearly determine its genetic basis, Huangzao4 and 
Mo17 were used as parental lines to detect the QTLs for EW under two $\mathrm{N}$ regimes. As a result, two QTLs from Huangzao4 were mapped on chromosomes 1 and 2.

Compared to previous reports, this study differed in many aspects, and the main differences are listed in Table 5. The parental line Huangzao4 possessing many agronomic merits including large EW and different $\mathrm{N}$ regimes was first used to identify the QTLs for EW. From the results, all ten chromosomes of maize harbored QTLs for EW, except for chromosomes 6 and 10, which suggests that EW is a quantitative trait controlled by multiple genes. However, the QTLs identified in different studies showed differences in many aspects including QTL number and position (Table 5).

\begin{tabular}{|c|c|c|c|c|}
\hline Reference & Parents & Population & Ecological regime & QTL number (Chr.) \\
\hline Frova et al., 1999 & B73, H99 & RIL & $\begin{array}{l}\text { Well water } \\
\text { Water stress }\end{array}$ & $\begin{array}{l}4(3,4,5 \text {, and } 8) \\
4(2,2,4, \text { and } 9)\end{array}$ \\
\hline Xiang et al., 2001 & Zong3, P138 & $\mathrm{F}_{2}$ & Two locations & $5(1,2,3,9$, and 9$)$ \\
\hline Xiao et al., 2005 & X173, B73 & $\mathrm{F}_{2}^{2}$ & $\begin{array}{l}\text { Well water } \\
\text { Water stress }\end{array}$ & $\begin{array}{l}2(1 \text { and } 9) \\
3(1,2 \text { and } 9)\end{array}$ \\
\hline Sabadin et al., 2008 & L-08-05F, L-14-4B & $\mathrm{F}_{2}$ & $\begin{array}{l}\text { Five environments } \\
\text { (location } \times \text { year combination) }\end{array}$ & $2(2$ and 7$)$ \\
\hline Guo et al., 2008 & $5003, \mathrm{p} 138$ & RIL & $\begin{array}{l}\text { Well water } \\
\text { Water stress }\end{array}$ & $\begin{array}{l}2(1 \text { and } 2) \\
0\end{array}$ \\
\hline This study & Huangzao4, Mo17 & RIL & $\begin{array}{l}\text { High nitrogen } \\
\text { Low nitrogen }\end{array}$ & $\begin{array}{l}1(2) \\
1(1)\end{array}$ \\
\hline
\end{tabular}

$\mathrm{RIL}=$ recombinant inbred line.

Besides us, other researchers have detected QTLs for EW on chromosomes 1 and 2 (Table 6). Nevertheless, our results still differ from those of the previous reports. For chromosome 1, no QTLs were detected by Frova et al. (1999) and Sabadin et al. (2008), while in our study, one QTL was mapped under LNR near Phi308707 (bin 1.10). Moreover, from the chromosome bin of flanking markers of these QTLs, it was concluded that the two QTLs identified in our study were new loci associated with EW in maize. These QTLs could be more precisely located using the RIL population that we developed, and the further study along this line is currently in progress.

Table 6. Bin loci of the flanking markers of the quantitative trait loci for ear weight on chromosomes 1 and 2 in maize.

\begin{tabular}{lrr}
\hline Reference & & Bin \\
\cline { 2 - 3 } & Chr. 1 & Chr. 2 \\
\hline Frova et al., 1999 & & $2.03-2.05,2.06-2.07$ \\
Xiang et al., 2001 & $1.02-1.03$ & $2.03-2.06$ \\
Xiao et al., 2005 & $1.02-1.03$ & $2.03-2.04$ \\
Sabadin et al., 2008 & & $2.03-2.03$ \\
Guo et al., 2008 & $1.07-1.07$ & $2.06-2.02$ \\
This study & $1.10-1.11$ & $2.08-2.09$ \\
\hline
\end{tabular}

In summary, maize inbred line Huangzao4 and two $\mathrm{N}$ regimes were first used to detect the QTLs for EW in this study. Under HNR, one QTL was identified on chromosome 2 near Bnlg1520 (bin 2.09), which could explain 7.46\% of phenotypic variance and an increase in EW of about $5.79 \mathrm{~g}$ owing to an additive effect. Under LNR, another QTL was identified on chromosome 1 near Phi308707 (bin 1.10), due to an additive effect, and it could account for $7.11 \%$ of phenotypic variance and a decrease in EW of $5.24 \mathrm{~g}$. The two QTLs from Huangzao4 
identified in our study are two new loci associated with EW, and the results are helpful in determining the genetic basis of EW in maize breeding projects.

\section{ACKNOWLEDGMENTS}

Research supported by Sichuan Science Foundation for Young Scientists (\#2007q14029) and Scientific Research Fund of Sichuan Provincial Education Department (\#08ZA020) of P.R. China.

\section{REFERENCES}

Cross HZ (1985). A selection procedure for ear drying-rates in maize. Euphytica 34: 409-418.

Frova C, Krajewski P, di Fonzo N, Villa M, et al. (1999). Genetic analysis of drought tolerance in maize by molecular markers I. Yield components. Theor. Appl. Genet. 99: 280-288.

Gilliland LU, Magallanes-Lundback M, Hemming C, Supplee A, et al. (2006). Genetic basis for natural variation in seed vitamin E levels in Arabidopsis thaliana. Proc. Natl. Acad. Sci. U. S. A. 103: 18834-18841.

Guo JF, Su GQ, Zhang JP and Wang GY (2008). Genetic analysis and QTL mapping of maize yield and associate agronomic traits under semi-arid land condition. Afr. J. Biotechnol. 7: 1829-1838.

Liu XH, Tan ZB and Rong TZ (2009). Molecular mapping of a major QTL conferring resistance to SCMV based on immortal RIL population in maize. Euphytica 167: 229-235.

Qi X, Niks RE, Stam P and Lindhout P (1998). Identification of QTLs for partial resistance to leaf rust (Puccinia hordei) in barley. Theor. Appl. Genet. 96: 1205-1215.

Ribaut JM, Fracheboud Y, Monneveux P and Banziger M, et al. (2007). Quantitative trait loci for yield and correlated traits under high and low soil nitrogen conditions in tropical maize. Mol. Breed. 20: 15-29.

Sabadin PK, Souza J, Souza AP and Garcia AAF (2008). QTL mapping for yield components in a tropical maize population using microsatellite markers. Hereditas 145: 194-203.

Voorrips RE (2002). MapChart: software for the graphical presentation of linkage maps and QTLs. J. Hered. 93: 77-78.

Wang HW, Li HJ, Zhu ZD and Wu XF, et al. (2009). Cloning and differential expression of QM-like protein homologene from maize. Acta Agron. Sin. 35: 1439-1444.

Wang S, Basten CJ and Zeng ZB (2010). Windows QTL Cartographer 2.5.Department of Statistics, North Carolina State University, Raleigh. Available at [http://statgen.ncsu.edu/qtlcart/WQTLCart.htm]. Accessed March 10, 2010.

Wu JY, Tang JH, Xia ZL and Chen WC (2002). Molecular tagging of a new resistance gene to maize dwarf mosaic virus using microsatellite markers. Acta Bot. Sin. 44: 177-180.

Xiang DQ, Cao HH, Cao YG, Yang JP, et al. (2001). Construction of a genetic map and location of quantitative trait loci for yield component traits in maize by SSR markers. Yi Chuan Xue Bao 28: 778-784.

Xiao YN, Li XH, George ML and Li MS, et al. (2005). Quantitative trait locus analysis of drought tolerance and yield in maize in China. Mol. Biol. Rep.155-165.

Zhao F, Meng XB, Li WH and Xu XD, et al. (2008). Inheritance relation of maize resistant genes among foundation parent huangzaosi and its derivative lines and hybrids. J. Maize Sci. 16: 15-18 